\title{
PCR Innovators Day: dreaming with our eyes wide open...
}

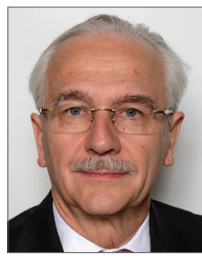

William Wijns ${ }^{1,2 *}, \mathrm{MD}, \mathrm{PhD}, \mathrm{FESC}$; David Cassak 3 ; Stephen Levin ${ }^{3}$

1. Cardiovascular Research Center Aalst, Aalst, Belgium; 2. Lambe Institute for Translational Medicine and Curam, National University of Ireland and Saolta University Healthcare Group, Galway, Republic of Ireland; 3. Medtech Strategist, Chatham, $N J$, USA

If "imaging is the eyes of the Heart Team", as Nicolo Piazza has so eloquently stated, then innovation is its most intimate dream - the waking dream of the interventionalist and clinician as they face the day-to-day challenges and unmet needs of their clinical practice. We all know that turning a dream into reality is not an easy enterprise, especially in medicine, where often the road from imagination to bench testing to the bedside can be a rocky and circuitous one.

PCR Innovators Day was created three years ago with this problematic in mind: to provide a special day when, together, we can focus on the act of creation in such a way as to move more easily from the concept of an unmet need to its practical, technical and effective clinical realisation. Experience has taught us that we cannot make this transition alone, either as clinicians or engineers or investors, but rather that it requires a sometimes subtle conjugation of diverse and essential talents - a juggling act allowing each individual their part in weaving the fabric of clinical reality.

\section{Creativity and innovation in the EuroPCR tradition}

EuroPCR has established a reputation for the quality of the exchange that occurs during the Course among the participants. By bringing this same quality to the world of innovation, we hoped to offer a practical approach that would truly be a "win-win" situation, in the best tradition of the PCR family. With 521 physicians, industry representatives, venture capitalists and engineers participating in this year's event, there was a general consensus that together we had created what Chaim Lotan describes as the "unique" environment necessary for innovation to exist.

A very specific set of conditions is necessary to do this, and the very nature of healthcare makes these conditions difficult to achieve. We have a field - medicine in general and interventional cardiology specifically - where we remain rightfully conservative concerning the adoption of new devices or techniques before they are fully proven. Complex anatomies and disease do not make creativity and innovation an easy task, and it is difficult to drum up the excitement required to attract the necessary money or inspire industry to follow and invest in a particular process or area of interest if we remain unsure of where it is going. This is constantly changing, as we see now in the mitral space, but it is only natural for people to be hesitant when others lack inspiration or confidence in a particular treatment.

\section{A subtle balancing act towards the future}

During PCR Innovators Day, the discussions followed, to some degree, the different themes of EuroPCR itself. Imaging is increasingly critical and, similar to the attention given to imaging technologies during the Course, was viewed with great 
interest in terms of the evaluation of the technologies themselves as well as the use of advanced imaging protocols in the selection and management of patients. Due to the importance of these new technologies of visualisation, many participants called on startups to consider integrating different imaging technologies within or in tandem with the other technologies they were developing. Safety, effectiveness, ease of use are all timeless challenges facing clinical technologies, and imaging can play a role here in validating a new technology, even before it comes into play after an intervention begins.

The interventional treatment of heart failure is in its infancy, but the tremendous and growing interest in this area was evident. Here we could look towards a future that might include the creation of a "Heart Failure Team" along the lines of the "structural" teams that have become so much a part of our practice today. Here innovation can learn from past experience and, instead of facing years of unnecessary competition between specialists, can look towards ways of working together and sharing expertise in order to enhance the desire for innovation and aid in a more rapid and smooth innovative process.

Integration of technologies, yes, of course, but integration of our various strengths and expertise as well - this too was one of the lessons of PCR Innovators Day as we look towards the future together.

Interventional Heart Failure treatment centres are another future promise with our cathlabs still waiting for the right innovative and novel devices. A mechanical answer to the question of what to do when drugs have failed in heart failure and hypertension remains to be fully answered and, while many devices are emerging here, this still remains a field that is very much in evolution. Devices for the early detection and diagnosis of heart failure point to the ongoing digital revolution and "e-health". This is a revolution that is about to happen and, like any revolution, the final rules that will govern it, after the dust settles, are still to be written, or are being written now in meetings like our own. Is this a generational question? Perhaps, but not completely, and, while we are not sure how it will all play out, one thing is certain, we have to prepare in advance, to ensure the protocols, to define the idea of cybersecurity in healthcare and to understand the nature of this new world. In a simple way the idea of "big data", which has already arrived, illustrates this well, where we see the difference between the modern world in which we speak of an experience encompassing hundreds of thousands of patients and one in which, only a generation ago, we would have spoken of dozens or hundreds.

In the arena of structural heart/valvular heart disease treatments, while we see TAVI dominated by first-generation devices, there is literally a "boom" in the development of mitral devices, especially for mitral replacement. Today alone, we have 16 devices that have been implanted in humans, with around five that have received the CE mark. Today we see more than 50 companies jockeying for position in the mitral and tricuspid space where innovative devices - and their accompanying questions - seem to be flourishing and which remains a challenging and rich frontier ripe for further innovation. The tricuspid area itself is taking off as well with the "leveraging" of some of the valves used in the mitral space, in addition to new, emerging dedicated devices.

PCR Innovators Day provides a forum for the critical questions that emerge concerning the innovations and treatments themselves. These questions are essential, involving, in the case of the mitral valve, such areas as the role of patient selection in choosing between either mitral repair or replacement; whether we will have the possibility to re-intervene, should the first intervention fail; the future importance of being able to combine repair-repair devices and repair-replacement devices; and the integration of imaging modalities in all these mitral devices and techniques, even before the procedure begins at the level of patient selection.

Another key aspect of innovation, and central to the realisation of the goals of all the different stakeholders involved, is moving from the unmet need and proposed technical solution to actual clinical use. To accomplish this requires evidence, and to have the data necessary we need to perform carefully designed and adequate clinical trials with, as an ultimate goal, understanding the procedure further and having it acknowledged as valid in our clinical guidelines. Nicolo Piazza noted that "clinical evidence fuels these guidelines" and that, in the 2012 ESC/EACTS guidelines on the management of valvular heart disease ${ }^{1}$, there was only one limited paragraph on transcatheter mitral valve interventions. He went on to say that "we cannot perform clinical trials if we do not have the proper endpoint definitions", something which was only defined with the 2015 publication of the consensus document from the Mitral Valve Academic Research Consortium (Mitral VARC) ${ }^{2}$. Now, with these definitions in place, over the next few years we expect to see a more rapid evolution in terms of evidence.

In conclusion, Nicolo Piazza reminded the attendees that if the SpaceX rocket was recently "able to go to space and land back on earth within literally metres of its target...in the future we will be able to perform transcatheter mitral valve interventions successfully" and that, though the "take-off" for these interventions may have begun slowly with only "approximately 100 performed since the first transcatheter mitral valve replacement in 2012, we should remember that there was also a slow start in TAVI, but today there are approximately 200,000 aortic valve interventions performed worldwide."

\section{A winning - and promising - device}

The importance of the mitral space as the current driver of innovation - as TAVI before it - cannot be underestimated. The winner of this year's poster for best innovation was by the American company HeartWorks LLC that developed the MitraClamp ${ }^{\mathrm{TM}}$, a device designed "to address mitral valve regurgitation due to mitral valve prolapse through a transcatheter approach". An innovative approach using u-shaped hooks, with rotating arms, it is the "only device today" that allows an "exclusion by plication" of the leaflet prolapsing area (Figure 1). Presented by Rachid Zegdi, MitraClamp ${ }^{\mathrm{TM}}$ was created for transseptal approach with 


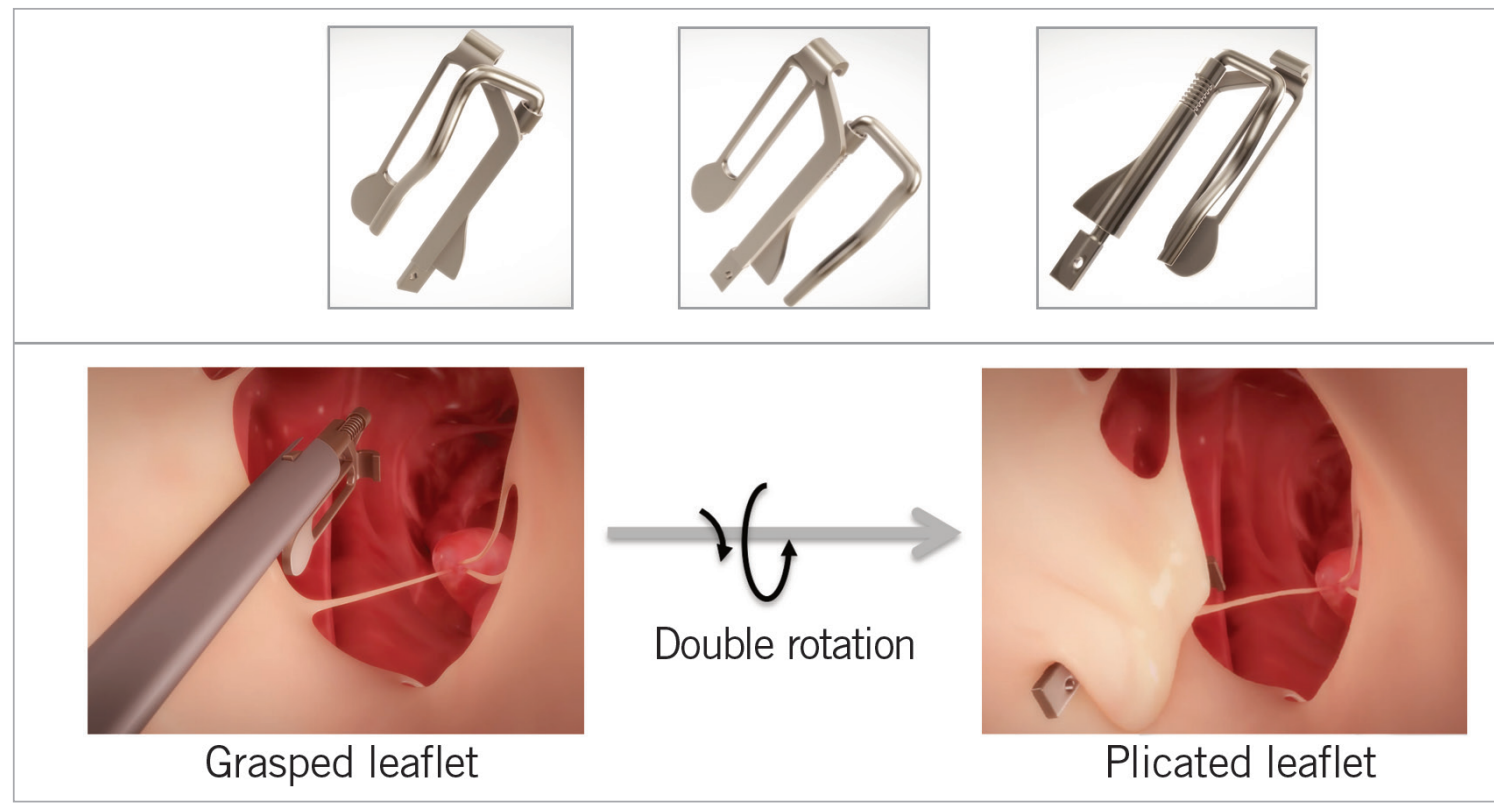

Figure 1. The MitraClamp ${ }^{\mathrm{TM}}$ was designed to treat patients with severe mitral regurgitation due to mitral valve prolapse. The device's u-shaped hooks, with rotating arms, allow an "exclusion by plication" of the leaflet prolapsing area.

the possibility of it being repositioned. It is currently undergoing animal studies before first-in-human implantation, expected within two years.

\section{Keeping the patient in the centre}

At the end of the day, there are still many questions to be asked. Do we have at our disposal the appropriate business models to encourage innovation? Who is the "customer" of the current technological and clinical developments: the patient? The government? The hospital or health provider? We are at a turning point when our paradigms seem to be changing, where the emerging markets are gaining force and maturity, where our regulatory and economic environment is changing as well... but, in the midst of all this flux, one thing needs to remain constant - the central role of the patient.

This was one of the lessons of letting ourselves dream with our eyes open - which is another way of describing what we do during PCR Innovators Day. Despite all our unmet needs, despite all the possibilities offered by emerging technologies, there is the constant reminder that these are simply tools: active clinical or decision-making tools they may be, but in no way do they release the individual physician from their responsibilities to their patient.

Often we will see that innovation is technology or investment driven, but in the end it has to be the individual doctor, working from a foundation of experience and evidence-based medicine, who will appraise what is needed and how it is to be used. This, together with the economic challenges of the present, makes moments like PCR Innovators Day all the more essential, when we can sit down both as individuals and as a group and let our dreams lead us to a better future.

\section{Conflict of interest statement}

W. Wijns received institutional research grants from AstraZeneca, Biotronik, Boston Scientific, Medtronic, MiCell, MicroPort, St. Jude, Terumo (Cardiovascular Research Center Aalst, Belgium), speaker fees from Biotronik, Medtronic and is a nonexecutive board member of Genae Inc. and Argonauts Partners. The other authors have no conflicts of interest to declare.

\section{References}

1. Joint Task Force on the Management of Valvular Heart Disease of the European Society of Cardiology (ESC); European Association for Cardio-Thoracic Surgery (EACTS), Vahanian A, Alfieri O, Andreotti F, Antunes MJ, Barón-Esquivias G, Baumgartner H, Borger MA, Carrel TP, De Bonis M, Evangelista A, Falk V, Iung B, Lancellotti P, Pierard L, Price S, Schäfers HJ, Schuler G, Stepinska J, Swedberg K, Takkenberg J, Von Oppell UO, Windecker S, Zamorano JL, Zembala M. Guidelines on the management of valvular heart disease (version 2012). Eur Heart J. 2012;33:2451-96.

2. Stone GW, Vahanian AS, Adams DH, Abraham WT, Borer JS, Bax JJ, Schofer J, Cutlip DE, Krucoff MW, Blackstone EH, Généreux P, Mack MJ, Siegel RJ, Grayburn PA, Enriquez-Sarano M, Lancellotti P, Filippatos G, Kappetein AP; Mitral Valve Academic Research Consortium (MVARC). Clinical Trial Design Principles and Endpoint Definitions for Transcatheter Mitral Valve Repair and Replacement: Part 1: Clinical Trial Design Principles: A Consensus Document From the Mitral Valve Academic Research Consortium. J Am Coll Cardiol. 2015;66: 278-307. 